\title{
Sharing the Indeterminate Space of Gender
}

\author{
Cristina Silvia VÂLCEA \\ Faculty of Letters, Transilvania University of Braşov (Romania) \\ Department of Theoretical and Applied Linguistics \\ cristina.valcea@unitbv.ro
}

\begin{abstract}
The in-betweenness of my research is the indeterminate space between being a man and talking like one and being a woman and talking like one. The control of that space is power-driven, and it consists of a permanent struggle to impose one's discourse as a strong marker of one's gender. Subliminally, gender takes control of one's discourse, impregnating it with the linguistic readily inherited data of manhood and womanhood. My research is an investigation of the discursive strategies that both men and women retort to when asked to state their opinion on different matters. Speech acts, vocabulary choices, liaising or showing empathy or, on the contrary, showing disinterest or taking distance will be interpreted in the framework of gender studies. The study has demonstrated that largely-held opinions of what is gender-specific talking are partially contradicted by the participants in the study, which proves my hypothesis right. Different factors, such as education or family background, influence personal speaking policies to the point of sharing features of the opposite gender. Far from being an issue that needs a clear separation, in-betweenness aims at mapping gender-specific and, if any, overlapping strategies in discourse.
\end{abstract}

Keywords: gender in-betweenness, linguistic indetermination

\section{Introduction and terminological clarifications}

The aim of this paper is to check my research hypothesis which states that men and women do not use language differently as linguistic features that have been considered traditionally masculine may easily appear in women's discourse and vice-versa. The limitation of linguistic features to either masculine or feminine appurtenance can be demonstrated by the rare linguistic specialization of men and women in the use of certain linguistic features. The issue of genderedlinguistic specialization will be investigated in this piece of research starting from the much-debated problem of gender. Talking about gender presupposes implicitly talking about sex from which gender has barely managed to separate. 
Nevertheless, sex has dominated the discussions about and the disputes between sexes for hundreds and hundreds of years. It was only in the twentieth century that attempts were made at distinguishing between sex and gender. Thus, a terminological clarification is necessary as long as some scientists use gender for sex for the only reason that gender seems to be a less loaded term. Consequently, in Oxford English Dictionary (Murray 1999: 786), sex is defined as "the sum of those differences in the structure and function of the reproductive organs on the ground of which beings are distinguished as male and female, and of the other physiological differences consequent on these; the class of phenomena with which these differences are concerned". On the other hand, gender can be defined as the behavioural, cultural, or psychological traits typically associated with one sex. The same dictionary defines gender as "either of the two sexes (male and female), especially when considered with reference to social and cultural differences rather than biological ones. The term is also used more broadly to denote a range of identities that do not correspond to established ideas of male and female". Conclusively, in the most basic sense, there is biological determination in sex, whereas there is cultural determination in gender.

The difference between sex and gender has made a valuable distinction between physical characteristics and psychological features, linguistic acquisitions, liaising skills and emotional manifestations of both men and women. Physical characteristics have proved insufficient and powerless in the attempt at explaining not so much the different male and female behaviour but the complex, fairly frequent cases when sexual features are exceeded by social, interpersonal, or linguistic characteristics. The addition of all these elements has made possible the transition from sex to gender as a more appropriate way to explain the complex situations where sex could offer explanations by simply postulating the differences between testicles and vagina. The perpetuation of the sex as the only differentiating criterion between men and women may have been maintained for such a long time due to its simple nature that could immediately tell between what is a man like and what is a woman like. Thus, stereotypes grew to characterize the expected behaviour of the two sexes, and whatever fell out of the largely accepted stereotypes would be easily defined as deviation. Fiske and Taylor (1984: 236) notice that individuality suffers because it is analysed according to the schema, which inevitably outlines and defines whole categories: "accumulated general knowledge about categories of people does not do justice to the unique qualities of any given individual, but it makes possible a certain amount of efficiency and adaptability to social cognition". Based on categories, stereotypes perpetuate a point of view on what men and women should behave like, talk like, dress like, etc. To illustrate this, Grimm (qtd in Cameron 1992: 46) alleges that the masculine equals to "earlier, larger, firmer, more inflexible, swift, active, mobile and productive", whereas the feminine means "later, smaller, the more still, suffering, receptive". In the same line, Graddol and 
Swann (1995: 68) claim that one's personality and way of being and behaving may suffer since one cannot be who s/he really is but rather someone the society wants to see: "[...] dominant images of femininity and masculinity, which encourage both women and men to seek gratification by conforming to established gender norms, lead ultimately to women's oppression. The way of speaking matches larger social visions about what femininity and masculinity are. Thus, women should take up gentle, nurturing roles, while men should be dominant and aggressive."

The encapsulation of sex into gender has done justice to one category, on the one hand, and has created a somehow blurred definition of what men and women are like and behave like on the other. Firstly, it has done justice to women as it has released them from the burden of marginalizing women to their corporality and to their culturally submitted social being. Secondly, it has blurred the previously strict and clear distinction between manhood and womanhood to the point of swapping features. Thus, in terms of gender, a man, besides the physical features that characterize him, may have other social, cultural, or linguistic features that previously were thought to be feminine (make-up, nail doing, chit-chatting, skirt wearing, leg or chest hair shaving, etc.). Similarly, a woman may have overcome her other-imposed limits, thus becoming a manager, wearing trousers, or controlling her speech. Yet, gender should not be seen as a total liberation from the control of stereotypes as gender itself has fallen under the rules of social definition of womanhood and manhood, which, though more permissive, impose rules, nevertheless.

\section{The speech of men and women}

Twentieth-century social and linguistic research revealed the existence of significant discrepancies between the way men and women used words. Sociolinguistics aims at identifying variations in discourse for different social categories on grounds of their education, age, social class, income level, and gender. Feminism, the emblematic trend meant to identify, explain, and popularize unfair or demeaning behavioural or communicative aspects when dealing with women, unlike men, who were considered the norm and against whom women would be assessed. Thirdly, Critical Discourse Analysis (CDA), interested mainly in revealing the ideologies behind most public messages, took a great interest in demonstrating the derogatory treatment of certain social categories of which women, children, and black people represent the core and who suffer discrimination.

Discrimination is both individual and collective as the individual is discriminated in person on grounds of his/her belonging to a certain group. Thus, each social category is strongly dependent on the stereotypes that the society at 
large has validated for that particular category. In terms of speech, stereotypes claim that men communicate straightforwardly, using simple structures, addressing directly their interlocutors, and being rather competitive. Women are said to talk more, to use more complex structures in communication, to be less direct, and more cooperative. Consequently, these features have been associated by Dragomir and Miroiu (2002: 104) with the competent group (the men) and to the warm/expressive group (the women). O'Sullivan claims that a stereotype is:

A label which involves a process of categorization and evaluation. Although it may refer to situations and places, it is most often used in conjunction with representations of social groups. In its simplest terms, as easily grasped characteristic, usually negative, is presumed to belong to a whole group, e.g. estate agents are insincere, devious and smoothtalking ... in ideological terms, stereotyping is a means by which support is provided for one group's differential treatment of another. (O'Sullivan qtd in Jones-Jones 1999: 105)

Men and women have been said to differ in their speech in a number of elements ranging from slightly to totally different. Of these, some illustrative examples have been selected and explained. Firstly, in the nineteenth and twentieth centuries, etiquette books, which aimed mainly at establishing what was the socially acceptable behaviour and spoken interaction desirable for women, were published. Women were advised to avoid social interaction on grounds that it was a woman-like behaviour. Etiquette books would rarely refer to men as there was no imposition on how they should behave or speak. Another opinion that stereotypically assigns different influences or uses of the language is that of Jesperson (1925: 27), who claimed that men, thanks to their lucrative activity, could invent new words, whereas women had a rather dulling effect on language. Thirdly, an iconic researcher of the phenomenon of gender discrimination, Lakoff (1975: 82), deemed that women are not inferior by birth, but they are trained to be inferior, showing that their inferiority is not innate but acquired from and transmitted by education. Fourthly, in terms of language use, women have been considered to use more colour and shades of colour names than men, who find it difficult to identify and name them. Women are also believed to use empty adjectives, such as "extraordinary" or "incredible", whereas men show preference for "consistent" words. Lastly, tag questions represent another point where it is supposed that men and women speech differs. Thus, it was claimed that women use extensively question tags, which signals their distrust in themselves, which supposedly justifies their need for confirmation.

Yet, there were other researchers who claimed that differences may exist between men's and women's speech, but they cannot be simply explained by 
their biological data. Education, culture, social and family background, exposure to knowledge may represent factors that have an impact on the way someone uses language, which illustrates the very aim of this article: to demonstrate that language elements that traditionally are believed to be used exclusively by either men or women are at times or frequently used by the opposite gender. This is because the multitude of elements that make a human being what he or she is can hardly respect the traditional framework for the masculine and feminine gender. And who says that it actually should?

\section{Questionnaire}

Starting from the traditional approach on gender, the aim of my research is to demonstrate that the border which supposedly separates the language of men and that of women is mostly an illusion, but certain people like to believe it exists or want to impose it. In fact, such elements are freely and interchangeably used by either men or women, mostly based on some external factors such as education, culture, social and family background, exposure to knowledge, and personality features. In order to demonstrate my hypothesis, I devised a 5-item questionnaire where I included questions that are likely to obtain prototypical answers from male and female respondents. Supposing this were the case, then my hypothesis would be wrong, which means that actually, when speaking, men and women use different strategies, different words, and different morphological and/or syntactic structures.

The first two items, "Describe in a few lines the maternal grandmother" and "Describe in a few lines the maternal grandfather" are meant to reveal the respondent's attitude to one's maternal grandmother/grandfather. It was expected that the respondents write a thorough description with details, characterizing adjectives. At the same time, male respondents are expected to provide shorter answers, to master and/or hide their feelings, whereas female respondents are expected to give more details, to write longer sentences, and to express their feelings to their grandmothers/grandfathers. The third item, "Because you cannot go to work, you write a message to your boss by which you inform him/her about your absence. Include all types of details that might justify your absence”, has been included as it might address another traditionally typological difference between men and women. Thus, when writing a message to one's boss/superior, men are largely expected to write short notes and to provide short reasons for their absence. Moreover, their degree of familiarity is expected to be higher than in the case of women, who are likely to use more formal formulas when addressing their boss. As women are supposed to be more talkative and willing to share different events of their lives, whereas men are usually said to not be 
so communicative, the fourth item, "You have had an extraordinary success at work. What sort of strategy do you use in order to make your success known to your colleagues, family, friends?”, is meant exactly to check if this assumption actually proves true for both men and women. The fifth item in the questionnaire, "Your best friend (of the same sex) is in a difficult situation. What would you tell him/her to sooth him/her? Would you act differently if your friend were of the opposite sex?", is meant to aim at same-sex communication and different-sex communication, which is regularly expected to run smoothly when in same-sex pairs or groups and rather less smoothly when in different-sex pairs or groups.

The respondents to my questionnaire are two married couples, which means that the participants are two men and two women. They were participants in one of my English courses, and I asked for their acceptance to participate in one of my pieces of research. It was not my intention to have married couples as respondents, but anyway, by marriage, there is no assumption that the way they think, talk, or write suffers any change. The small number of participants, thus a limit to my piece of research, comes as a consequence of the fact that the adult group I was teaching at the time of the data selection was a small one, and some course participants expressed their desire of not participating.

Due to the reduced number of respondents, to the fact that the data are authentic, and that theory and research data are fused, I consider that the type of research that I carry out is qualitative (Neuman 2014: 82). Though the research includes some quantitative data, the focus is on the elements that blur the supposedly existing border between the feminine and masculine use of the language. Secondly, my research is a small-scale research that could confirm or infirm my hypothesis against the traditional concept that men and women speak two different languages with different means and to different ends. Thirdly, the purpose for carrying out this piece of research is not to claim the failure of the traditional approach of sex-specialized use of language but to state that in some cases, of which this could be one, that hypothesis may not cover all possible communication situations.

\section{Findings}

The analysis of the collected data begins by stating that there are going to be both inter-gender considerations (as the intention is to identify similarities and dissimilarities between my male and female respondents) and intra-gender considerations (as I would not miss the opportunity of highlighting the existence, if any, of some dissimilarities between the male and the female respondents). I will analyse the data according to certain criteria: length of the response (habitually, men are thought to give shorter, more concise answers, whereas 
women are considered to formulate longer answers), number of adjectives used in descriptions (usually, men are said to use a reduced number of adjectives, whereas women use adjectives extensively), degree of formality (men are said to be less formal, whereas women are considered to be more formal), (in)security, and empathy, cooperative or competitive interpersonal behaviour.

In order to facilitate data manoeuvring, I have decided on some coding to indicate the gender, as in $\mathrm{M}$ for male and $\mathrm{F}$ for female, doubled by a number to indicate if it is the first or the second male or female respondent.

\subsection{Length of the response}

As formerly indicated, men and women are supposed to produce chunks of language of appreciatively different lengths based on the unique criterion of gender. Thus, as the theory goes, men produce shorter chunks of language due to their innate scarcity for words, which they consider enough to communicate efficiently.

On the other hand, women produce longer chunks of language due to their innate verbosity and to the great quantity of empty words that women use for the sake of embellishing their discourse rather than rendering it more effective.

Against this background, my research, though of a small sample size, brings along elements that both confirm and infirm the traditional approach. One of the male respondents, M1, perfectly illustrates the traditional approach that men do not use many words in their communications. Actually, in this case, the answer to the first two questions, when they were asked to describe their maternal grandparents, is reduced to one word, "severe" (to describe his maternal grandmother) and "intelligent" (to describe his maternal grandfather).

Contrastively, the second male respondent, M2, offers an incomparably longer answer, which contains some details and more complex grammatical structures (a number of characterizing adjectives, a variety of tenses, complex deductive modals, and means of expressing cause).

M1 - Q1 - "Severe" WC (1)

- Q2 - "Intelligent" WC (1)

M2 - Q1 - "Gentle, warm-hearted character. We didn’t interact so much due to the distance that separated us. Anyway, we were extremely happy when we met." WC (23)

- Q2 - "He was a tougher person, he had been at war and that must have influenced him.

He would rarely play with us, and at night he was the only one capable to put us to bed."WC (36) 
Elseways, the female respondents have both confirmed the largely held ideas that women talk more and communicate extensively. With few exceptions when the sentences are incomplete, all the other sentences are complete (Greenbaum 1996: 23), full sentences that aim at building a portrayal of the grandparents. Similarly, the variety of grammatical structures and the complexity of the morphology and syntax are to be noticed.

F1 - Q1 - "Very hard-working and determined in everything she used to do. Perfect housewife. Slightly domineering as a woman, but, as my grandmother, she used to spoil me a lot.” WC (28)

- Q2 - "Being a teacher, he used to be patient and permissive. Pretty sensitive. Willing to help whomever he could." WC (18)

F2 - Q1 - "My grandmother is 80, and she feels lonely and helpless all the time, even when there is someone with her. She worked a lot in her life, and now she neglects herself, she expects to be treated as a child." WC (40) - Q2 - "My grandfather was a respected man, and he liked jokes." WC (10)

Table 1. Length of the response

\begin{tabular}{|c|c|}
\hline Respondent & Word Count \\
\hline \multirow{2}{*}{ M1 } & $\mathrm{Q} 1-1$ \\
\hline & $\mathrm{Q} 2-1$ \\
\hline \multirow{2}{*}{ M2 } & $\mathrm{Q} 1-23$ \\
\hline & Q2-36 \\
\hline \multirow{2}{*}{ F1 } & Q1 - 28 \\
\hline & $\mathrm{Q} 2-18$ \\
\hline \multirow{2}{*}{ F2 } & $\mathrm{Q} 1-40$ \\
\hline & $\mathrm{Q} 2-10$ \\
\hline
\end{tabular}

If in this particular case the two women respondents confirm the claim that women communicate more than men, there is a blatant difference between the two male respondents; while one of them confirms the already proverbial shortness of men's communication, the other one is, by his way of communication, closer to women's way of communication. This is a first confirmation of the research hypothesis of this article: being a man or a woman does not necessarily circumscribe you to the communication means, skills that stereotypically are said to be used by men or women. Gender is more than sex. 


\subsection{The number of adjectives used in descriptions}

Adjectives are characterized in the Cambridge Grammar of the English Language as expressions "that alter, clarify, or adjust the meaning contributions of nouns". Deborah Tannen (1990: 45), Jennifer Coates (1998: 78), and Janet Holmes (2001: 96) carried out research which claims that women use a higher number of adjectives due to the "emotional language" that women are more likely to use. Moreover, it was claimed that in some cases the adjectives were "empty adjectives" - namely, they are adjectives that do not add any meaningful content to the context, but they try to soften or attenuate some tougher structures.

Thus, in a comparative study, women are expected to use more adjectives than men due mainly to their cooperative speaking style, whereas men are expected to use fewer adjectives due to their competitive speaking style. To the request of describing their maternal grandfather, respondents chose different ways of dealing with it. Thus, the first male respondent described the maternal grandfather by only one adjective: "intelligent", but the second male respondent gave a longer answer, and so did the female respondents.

A simple identification of the adjectives in each answer shows that there are two respondents, a male (M1) and a female (F2), whose descriptions contain one adjective. The other male respondent (M2) used 2 adjectives, and the other female respondent (F1) used 4 adjectives. Judging by the number of adjectives used by three of the respondents, it is very difficult to assert that either category is more or less inclined in using adjectives. The exception that could actually confirm the opinion that women use adjectives extensively is represented by F1, who uses 4 adjectives to describe her maternal grandfather.

M1 - Q2 - "Intelligent"

M2 - Q2 - "He was a tougher person, he had been at war, and that must have influenced him.

He would rarely play with us, and at night he was the only one capable to put us to bed."

F1 - Q2 - "Being a teacher, he used to be patient and permissive. Pretty sensitive. Willing to help whomever he could."

F2 - Q2 - "My grandfather was a respected man, and he liked jokes."

\subsection{Degree of formality}

The discussion of women's using more formal structures than men started with Trudgill (1972: 120), who claimed that female respondents use more "prestige standard forms more frequently than men". In this piece of research, the respondents gave written answers, and it is rather unlikely that they might have used slang or 
serious grammatical deviation. Nevertheless, as the respondents were asked to write a note to their boss wherein to inform that they could not come to work that day, there are some elements that relate to formality/informality. The first element taken into consideration is the addressing formula: M1 and F2 used a friendly addressing formula, "hi", which is a marker of informal communication. F1 did not use any addressing formula, but she used a greeting formula: "good morning".

The only formal addressing formula is used by M2, who begins with the formula 'Dear Mr. manager", thus using what is largely believed to be a formal formula for addressing your boss. All the respondents end their note by thanking their boss. Still, the way they do it is different in terms of formal/informal formulas. So, M1 and F2 end their note with "Thanks", which is an informal way of thanking. M2 and F1 use "Thank you", which is considered to be formal. M1, M2, and F2 used at some point the emphatic politeness formula "please", whereas F1 never uses it. Of the four respondents, it is only M2 who used the ending formula "yours", which is a must-have element in formal pieces of writing. Based on the available data, it is difficult to claim conclusively that the female respondents in this study use more formal structures than men do. On the contrary, the notes prove that the two female respondents use more informal structures than, at least, one male respondent.

M1 - Q3 - Hi, Marius!

Please, allow me not to come to work today. I have got some personal issues that can't be postponed to solve.

Thanks a lot for your kindness.

Have a good day!

M2 - Q3 - Dear Mr. Manager,

Today, I will not be able to come to work because my child had high fever last night, my wife is on a delegation, and our family doctor is available only in the morning.

Thank you for being so understanding.

I will recuperate these lost hours, or, if you can, please agree on a leave day. Yours,

F1 - Q3 - Good morning, unfortunately I cannot come to office today because my daughter has got sick and needs my attention.

I am very sorry, but I will try to recuperate in the coming days.

Thank you for being understanding.

F2 - Q3 - Hi! Sorry to bother you. I've got some emergency tomorrow morning. Please, allow me to not come tomorrow between 8 and 10. Thanks. 


\section{4. (In)security}

The fourth question in the questionnaire was meant to obtain some important data on how the respondents would inform family and friends about their success. The purpose behind this request was an indirect one and hard to guess by the respondents. In psychology, it is claimed that those who feel the need to externalize their achievements are those who feel insecure about their capacity of actually achieving something important (Correa-Willard-de Zuniga 2009; DeWall-Buffardi-Bonser-Campbell 2011; Gentile-Twenge-Freeman-Campbell 2012). To externalize an achievement is equal to a confirmation of one's capacity to achieve goals and to a chance to prove everyone one's capacity.

Therefore, the higher the urge to externalize, the higher the insecurity, and the lower the urge to externalize, the lower the insecurity. On the other hand, Hite (1987: 153) claims in a report that has become famous that it is the women the ones who are believed (by men) to be weak, to need reassurance and help, to be overly emotional. So, according to men, women are: "pushy, demanding, complaining, neurotic, behaving like a prima donna, narcissistic, vain, bitchy, self-indulging, hysterical, screaming, irrational, petty, needing reassurance, overly emotional, aggressive, too sensitive".

At a first glance, it is immediately noticeable that all respondents would choose to break the news of the achievement to family or friends/colleagues. It is important to notice that three out of four respondents break the news personally in a personalized manner; thus, M1 simply tells everybody about it (the implicature may be that there is no much fuss about it), M2 does not answer directly to the question and focuses on the fact that the achievement should be celebrated - so, he focuses on where and whom he would invite. F1 chooses to downsize her importance, but she would nevertheless break the news "so that they know" not because she wants to be appreciated. Interestingly enough, F2 chooses to break the news online by sharing it via either social networks or groups of friends.

M1 - Q4 - I simply tell them.

M2 - Q4 - At weekend, I will invite the entire family and friends for a party at a chalet in the mountains. My co-workers will be invited to a restaurant in the town.

F1 - Q4 - I am not used to being very enthusiastic about myself, and I would simply tell them what I have achieved or obtained, so that they know.

F2 - Q4 - I would post on social[izing] networks, I would send messages to my groups of friends. 


\subsection{Empathy, cooperative, competitive}

Sociolinguists from Lakoff (1975: 87) to Wodak (1997: 386) claimed that due to their gentleness, to their nurturing availability, women are more likely to be more empathetic than men. To be empathetic means to care about the ones around you, and women are apparently endowed to a higher degree with empathy rather than men. Medical studies (Mestre-Samper-Frias-Tur 2009: 78) have been carried out to test if empathy is an innate or acquired quality. The results have demonstrated that empathy is acquired, and the means of acquisition is family and school education, which, stereotypically, teaches girls to be nurturing, whereas boys are taught to be strong, not to cry, and to master their feelings.

Consequently, by the fifth question in the questionnaire, the assumption that women are more emphatic than men is challenged. In order to check the respondents' empathy, they have been asked to specify their stand when facing the following situation: "Your best friend (of the same sex) is in a difficult situation. What would you tell him/her to sooth him/her? Would you act differently if your friend were of the opposite sex?" M1, M2, and F2 state that they would react similarly irrespective of the sex of the friend who is in a difficult situation. Contrarily, F1 asserts that her reaction would be different if she had to deal with a friend of a different sex. In this particular case, the sex of the friend may represent an obstacle to empathy. M1 indicates encouragement as the soothing solution. M2 suggests communication, interconnection with other friends for the common goal of finding a solution. F1 indicates as solutions listening to her friend, talking, accompanying her, if necessary. F2 manifests her interest in the tough situation of her friend.

M1 - Q5 - I try to encourage him or her.

M2 - Q5 - I try to make him communicate the problem he has got so that we find together a solution that might help him. I will also try to talk to other friends if I cannot solve the problem by myself. I would act similarly in the case of a female friend.

F1 - Q5 - I would tell her that I understand her and that I am close to her. That if she needs help I am available at all times. I would listen to her, if she feels the need to talk or I would stay with her if she wishes [to]. If my friend were of a different sex, I think that I would be more reserved. I would maintain certain limits in offering my services.

F2 - Q5 - I understand you are in a tough situation. How could I help you? I guess the approach would be similar. 


\section{Conclusions}

The focus of this article is to check the hypothesis of the blurred borderline between the (socio)linguistic manifestations of men and women. This approach opposes the traditional perspective that men come from Mars and women from Venus, actually implying that the way men and women use language and behave while using the language is totally different. The hypothesis of this article was that men and women are not circumscribed to all-men or all-women linguistic choices, which put serious obstacles to all those that might want to use structures belonging to the other group. Language is a huge combinatory bag from which men and women extract words and structures according to their (family) education (which might indeed impose certain gender-bound structures), age, cultural background, entourage, etc.

Though of small size, the research attempts at testing the hypothesis of the blurred borderline, and the results confirm the hypothesis. The first element that was tested was the number of words that men and women use in ordinary written communication. The results indicated that both F1 and F2 use more words in the description of their grandfathers than M1, who uses only one word, but M2 uses more words in his answer to Question 2, and he is quite close to F1 and F2 when answering Q1. Is M2 a better communicator than M1? It could be, but, according to traditional sociolinguistic research, men are limited in the quantity of words used when communicating. On the other hand, M1 is an illustration of men's directness and scarcity in word use. When answering Q1, both F1 and F2 use more words than men, but they are both outnumbered by M2.

As for the number of adjectives as an indicator of the sex, the data of the research is highly inconclusive as it confirms again the blurredness of language specialization and separation on the criterion of sex. M1 and F2 use an equal number of adjectives, that is: 1 , while F1 stands out by a number of 4 adjectives. M2 uses 2 adjectives. The data do not indicate a clear gender-based separation in as far as the number of adjectives is concerned.

As to formality, which is believed to be an advantage of women, this research has shown that for these respondents things are also mixed. M1 and F2 use an informal greeting formula, "Hi", F1 does not use any greeting, whereas M2 is highly formal. Similarly, M1 and F2 use "thanks", the informal variant of "thank you", which is preferred by M2 and F1. This is but another element which contradicts the largely held opinion that women are more formal than men.

When it comes to (in)security, which manifests by one's going viral, the data in the research show that M1, M2, and F1 pay no or little attention to their achievement from the perspective of making it public. Yet, F2 shows her interest in making her success known online. That might partly confirm that women who feel insecure brag about their achievements as the only way of proving their skills. 
As far as empathy is concerned, women are said to be more empathetic than men as they usually nurture those around them. The data in the research show that all respondents show empathy to their friends in varying degrees. M1 and F2 indicate that they are interested in the problems of their friends, but their empathy is limited to some encouragements. Contrarily, M2 and F1 act more seriously and profoundly, suggesting further measures that they would take when facing a friend in a difficult situation.

The situation is rather inconclusive in the majority of situations under analysis, which could only signal the entrapment of theories that claim and maintain that men and women either use language differently or they react differently to similar situations. It would be wrong, though, to deny the existence of any variation in language use between men and women, which is exactly an illustration of the inbetweenness of gender linguistic manifestations.

\section{References}

Cameron, Deborah. 1992. Feminism and linguistic theory. London: Palgrave Macmillan.

Coates, Jennifer. 1998. Language and gender: A reader. London: Willey.

Correa, Teresa-Willard, Amber-de Zuniga, Homero. 2009. Who interacts on the web?: The intersection of users' personality and social media use. Computers in Human Behavior 26: 247-253.

DeWall, Nathan-Buffardi, Laura-Bonser, Ian-Campbell, Keith. 2011. Narcissism and implicit attention seeking: Evidence from linguistic analyses of social networking and online presentation in personality and individual differences. Computers in Human Behavior 51: 57-62.

Dragomir, Otilia-Miroiu, Mihaela. 2002. Lexicon feminist. Iaşi: Polirom.

Fiske, Susan-Taylor, Shelley. 1984. Social cognition. Random House: New York.

Gentile, Brittany-Twenge, Jean-Freeman, Elise-Campbell, Keith. 2012. The effect of social networking websites on positive self-views: An experimental investigation. Computers in Human Behavior 28: 1929-1933.

Graddol, David-Swann, Joan. 1995. Feminising classroom talk? In: S. Mills (ed.), Language and gender. London: Longman.

Greenbaum, Sidney. 1996. Oxford English grammar. London: Clarendon Press.

Hite, Shere. 1987. Women and love - The Hite Report. London: Penguin.

Holmes, Janet. 2001. An introduction to sociolinguistics. London: Pearson Education.

Jesperson, Otto. 1925. Mankind, nation and individual: From a linguistic point of view. London-New York: Routledge.

Jones, Marsha-Jones, Emma. 1999. Mass media. London: MacMillan. 
Lakoff, Robin. 1975. Language and woman's place. London: Oxford University Press.

Mestre, Vicenta-Samper, Paula-Frias, Maria Dolores-Tur, Ana Maria. 2009. Are women more empathetic than men? A longitudinal study in adolescence. NCBI resources 12: 76-83.

Neuman, Lawrence. 2014. Social research methods: Qualitative and quantitative approaches. London: Pearson.

Tannen, Deborah. 1990. You just don't understand. New York: Ballantine Books. Trudgill, Peter. 1972. Sex, covert prestige and linguistic change in the urban British English of Norwich. Language in society 1(2): 179-195.

Wodak, Ruth. 1997. Gender and discourse. London: Sage Publishing.

\section{Dictionaries}

Murray, James (ed). 1999. Oxford English dictionary. London: Oxford University Press. 